\title{
Quantitative estimates of velocity sensitivity to surface melt variations at a large Greenland outlet glacier
}

\author{
M.L. ANDERSEN, ${ }^{1,2}$ M. NETTLES, ${ }^{3}$ P. ElOSEGUI, ${ }^{4}$ T.B. LARSEN, ${ }^{1}$ G.S. HAMILTON, ${ }^{5}$ \\ L.A. STEARNS ${ }^{6}$ \\ ${ }^{1}$ Geological Survey of Denmark and Greenland, Øster Voldgade 10, DK-1350 Copenhagen, Denmark \\ E-mail: mola@geus.dk \\ ${ }^{2}$ Centre for Ice and Climate, University of Copenhagen, Juliane Maries Vej 30, DK-2100 Copenhagen, Denmark \\ ${ }^{3}$ Lamont-Doherty Earth Observatory, Columbia University, Palisades, New York 10964-8000, USA \\ ${ }^{4}$ Institute for Space Sciences (ICE) and Marine Technology Unit (UTM), CSIC, \\ Passeig Marítim de la Barceloneta 37-49, ES-08003 Barcelona, Spain \\ ${ }^{5}$ Climate Change Institute, University of Maine, 303 Bryand Global Sciences Center, Orono, Maine 04469-5790, USA \\ ${ }^{6}$ Department of Geology, University of Kansas, 120 Lindley Hall, 1475 Jayhawk Blvd, Lawrence, Kansas 66045-7613, USA
}

\begin{abstract}
The flow speed of Greenland outlet glaciers is governed by several factors, the relative importance of which is poorly understood. The delivery of surface-generated meltwater to the bed of alpine glaciers has been shown to influence glacier flow speed when the volume of water is sufficient to increase basal fluid pressure and hence basal lubrication. While this effect has also been demonstrated on the Greenland ice-sheet margin, little is known about the influence of surface melting on the large, marine-terminating outlet glaciers that drain the ice sheet. We use a validated model of meltwater input and GPS-derived surface velocities to quantify the sensitivity of glacier flow speed to changes in surface melt at Helheim Glacier during two summer seasons (2007-08). Our observations span $\sim 55$ days near the middle of each melt season. We find that relative changes in glacier speed due to meltwater input are small, with variations of $\sim 45 \%$ in melt producing changes in velocity of $\sim 2-4 \%$. These velocity variations are, however, of similar absolute magnitude to those observed at smaller glaciers and on the ice-sheet margin. We find that the glacier's sensitivity to variations in meltwater input decreases approximately exponentially with distance from the calving front. Sensitivity to melt varies with time, but generally increases as the melt season progresses. We interpret the time-varying sensitivity of glacier flow to meltwater input as resulting from changes in subglacial hydraulic routing caused by the changing volume of meltwater input.
\end{abstract}

\section{INTRODUCTION}

Multiple observational and modeling studies show that the Greenland ice sheet is losing mass (e.g. Chen and others, 2006; Luthcke and others, 2006; Velicogna and Wahr, 2006; Rignot and others, 2008; Van den Broeke and others, 2008). In current estimates of the mass budget of the ice sheet, drainage in the form of iceberg calving from the termini of outlet glaciers accounts for $\sim 50 \%$ of the total mass loss (Krabill and others, 2004; Rignot and others, 2008; Van den Broeke and others, 2008). Modeling and prediction of this calving flux is complex and has not yet been fully accomplished, though understanding controls on dynamic ice loss is critical for improved predictions of sea-level rise and ice-sheet drawdown.

The ice volume drained through Greenland's outlet glaciers is related to their flow speed. Controls on rapid changes in glacier flow speed are only beginning to be understood. It is now clear that the flow velocity of Greenland's large, marine-terminating outlet glaciers responds to ice loss at the glacier terminus on interannual (e.g. Howat and others, 2005), seasonal (e.g. Joughin and others, 2008a) and shorter (Amundson and others, 2008; Nettles and others, 2008) timescales.

A number of studies conducted on the margin of the West Greenland ice sheet suggest that variations in surface melting also play an important role in modulating sliding speed and controlling observed surface velocities. On the ice sheet near Swiss Camp, north of Jakobshavn Isbræ, Zwally and others (2002) observed acceleration of ice flow associated with summer melting. Van de Wal and others (2008) observed speed variations of up to $30 \%$ along the K-transect near Kangerlussuaq during 2005/06, and Shepherd and others (2009) found flow-speed increases on the ice sheet of up to $35 \%$ per positive degree-day in the same area. On Russell Glacier, a land-terminating outlet glacier in West Greenland, Bartholomew and others (2010) observed summer surface velocities as much as $220 \%$ faster than the $\sim 100 \mathrm{~m} \mathrm{a}^{-1}$ winter background speed in association with peaks in local temperature. Similarly large effects have been observed on alpine glaciers (e.g. Iken and Bindschadler, 1986; Anderson and others, 2004) and tidewater glaciers outside Greenland (e.g. Kamb and others, 1994; Meier and others, 1994). A suggested mechanism for such increases in flow speed is the drainage of surface meltwater to the ice/ rock interface via fracture propagation (Van der Veen, 2007), leading to enhanced basal sliding (Zwally and others, 2002; Fountain and others, 2005; Das and others, 2008).

Less is known about the response of Greenland's fastflowing marine-terminating outlet glaciers to changes in meltwater input. An early remote-sensing-based study by Joughin and others (1996) described the occurrence of a meltwater-induced acceleration pulse on Ryder glacier, a relatively slow-moving $\left(20-150 \mathrm{~m} \mathrm{a}^{-1}\right)$ marine-terminating outlet glacier in North Greenland, demonstrating that such 
glaciers might be affected by meltwater input. Using both remote-sensing and field-based techniques to analyze the ice-sheet margin and several outlet glaciers, Joughin and others (2008b) found seasonal accelerations of 50-100\% on the ice sheet, with fractionally smaller variations of $9-14 \%$ on the outlet glaciers. However, Joughin and others (2008b) treated the outlet glaciers en masse, and did not separate calving-related and melt-related accelerations. A recent remote-sensing study by Howat and others (2010) described the intra-seasonal velocity variability of a group of West Greenland marine-terminating outlet glaciers, finding that, for non-retreating glaciers, a spring speed-up was followed by a gradual slowdown as the melt season progressed. Howat and others (2010) interpreted these speed changes as indicative of the drainage system becoming increasingly efficient, adapting to the increasing supply of meltwater. Andersen and others (2010) used velocity estimates from GPS data and the output of a calibrated melt model to demonstrate a correlation between day-to-day variations in meltwater production and the flow speed of Helheim Glacier, a large, marine-terminating outlet glacier in East Greenland. Andersen and others (2010) also found some indication of spatial variability, with correlations stronger near the front than upstream. While all of these studies suggest that meltwater variations are likely to affect the flow speeds of Greenland's marine-terminating outlet glaciers, on a variety of timescales, little is known quantitatively about the sensitivity of velocity variations to melt variations, or about spatial and temporal changes in this sensitivity. Understanding this response, and its relative and absolute contributions to increased ice-discharge rates, is important for developing a more complete picture of the ice sheet's likely response to changes in environmental conditions.

Here we use the data of Andersen and others (2010) to quantify the velocity sensitivity of Helheim Glacier to variations in input of surface meltwater, using a simple, linear model. We address some of the questions raised by Andersen and others (2010) by evaluating both spatial and temporal variations in the glacier's responsiveness to meltwater input and interpret the results in terms of possible variations in subglacial hydrology.

\section{DATA}

During the summers of 2007 and 2008 we collected several geophysical datasets at and around Helheim Glacier, including GPS measurements of glacier surface position and meteorological observations at an automatic weather station (AWS) on the glacier. The time series span $\sim 55$ days from late June or early July to late August in each year. Daily mean temperatures in 2008 recorded by the Danish Meteorological Institute (www.dmi.dk) $\sim 100 \mathrm{~km}$ from the glacier in the town of Tasiilaq rose above $0^{\circ} \mathrm{C}$ in early May (day 127) and fell below $0^{\circ} \mathrm{C}$ in early October (day 280 ). The best estimate for the duration of the melt season at Helheim Glacier, at higher elevation, is therefore within these bounds, but likely to be somewhat shorter. Our observation time window captures approximately the middle third of the melt season, but neither end-point.

We also recorded time-lapse photographs of the glacier front and water-level variations in the glacial fjord. This combination of datasets allows us to assess the spatially and temporally varying influence of melt on flow speed during the period of our observations. We are unable to assess long-term, seasonal or interannual variations, given the limited time-span of our data and the many other possible controls on glacier flow speed on those timescales, including variations in ice melange (e.g. Amundson and others, 2010; Howat and others, 2010), and high fjord water temperatures (Straneo and others, 2010).

\section{Glacier surface velocity}

We deployed a network of 12-22 continuously recording GPS receivers on Helheim Glacier during the summers of 2007 and 2008, for 54 and 55 days, respectively (Fig. 1). The networks extended from within a few $\mathrm{km}$ of the calving front to $\sim 20 \mathrm{~km}$ upstream along the flowline in 2007 and $\sim 30 \mathrm{~km}$ in 2008. Daily velocities were calculated by fitting a linear model to position estimates determined kinematically at $15 \mathrm{~s}$ intervals, as described by Nettles and others (2008). The velocity estimates have uncertainties of $\sim 0.1 \mathrm{~m} \mathrm{~d}^{-1}$.

The loss of ice from the glacier terminus during largescale calving events has been shown to change the flow speed by as much as 20\% at Helheim Glacier (Nettles and others, 2008) and elsewhere (Amundson and others, 2008). The effect of calving events on glacier speed must therefore be quantified and removed from the velocity signals in order to study the effect of melt on speed variations. The largest changes in daily glacier velocity are associated with calving events for which glacial earthquakes are detected (Nettles and others, 2008) and these changes appear in the velocity record as step-like offsets. To identify the times when calving-related velocity offsets may occur, we use the list of glacial earthquakes from Nettles and others (2008) for events in 2007, and a list of events for 2008 identified in a similar manner, using the algorithm of Ekström (2006). In 2008, we identify two $M \sim 4.8$ seismic events at Helheim Glacier on day 214 and one event of $M \sim 4.7$ on day 232, as well as several smaller events (Fig. 2).

Some calving-related velocity increases observed by Amundson and others (2008) were not associated with glacial-earthquake detections (Nettles and Ekström, 2010). In 2008, we made observations of calving events using a time-lapse camera mounted on the northern wall of the Helheim fjord. The camera was configured to record images automatically every $4 \mathrm{~min}$. Major calving events were identified by visual inspection (Hamilton and others, 2008), and we assume an uncertainty of \pm 30 min on the timing of these events due to their finite duration and the image-sampling rate.

We also deployed a water-pressure tide gauge to monitor variations in water level, sampling at $1 \mathrm{~min}$ intervals. The instrument was installed at an island in the fjord, $\sim 25 \mathrm{~km}$ from the calving front. Calving events at the glacier front produce tsunami signals in the tide-gauge record, which we use to verify our visual and seismic detections of major calving events.

The combined calving dataset for 2008 that we use to correct the velocity signal for calving-related velocity changes is shown in Figure 2, with the detected glacial earthquakes marked with red lines, the calving events observed from the photographs marked with black lines, and the tide-gauge data bandpass-filtered from 200 to $4000 \mathrm{~s}$ in blue. Smaller arrivals in the tide-gauge record not associated with detected calving events are assumed to be caused by icebergs rolling or breaking into several pieces, thereby causing disturbances in the water level. For the year 2007 we do not have time-lapse photography available, so we use 

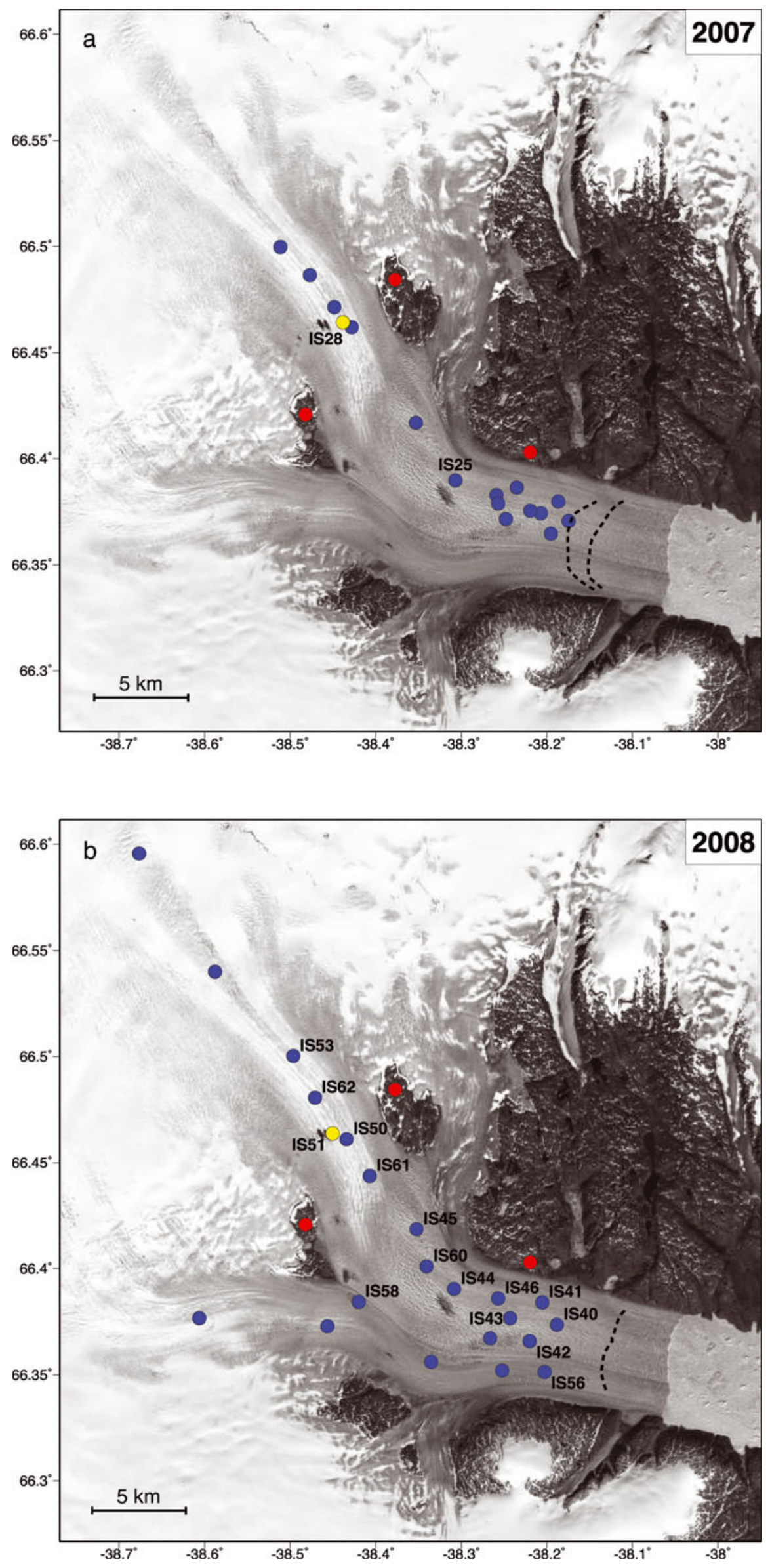

Fig. 1. 2007 (a) and 2008 (b) GPS receiver network geometry and AWS location on Helheim Glacier, overlain on a 2001 Landsat image. Dots mark the position of (blue) GPS ice sites, (yellow) co-located AWS and GPS sites and (red) GPS reference sites. Dotted lines are calvingfront positions on (a) 4 July 2007 (easternmost) and 24 August 2007, both from MODIS images, and (b) 31 July 2008, from field observations. The dark area immediately west of IS28 (2007) and IS51 (2008) is a yearly recurring meltwater lake. 

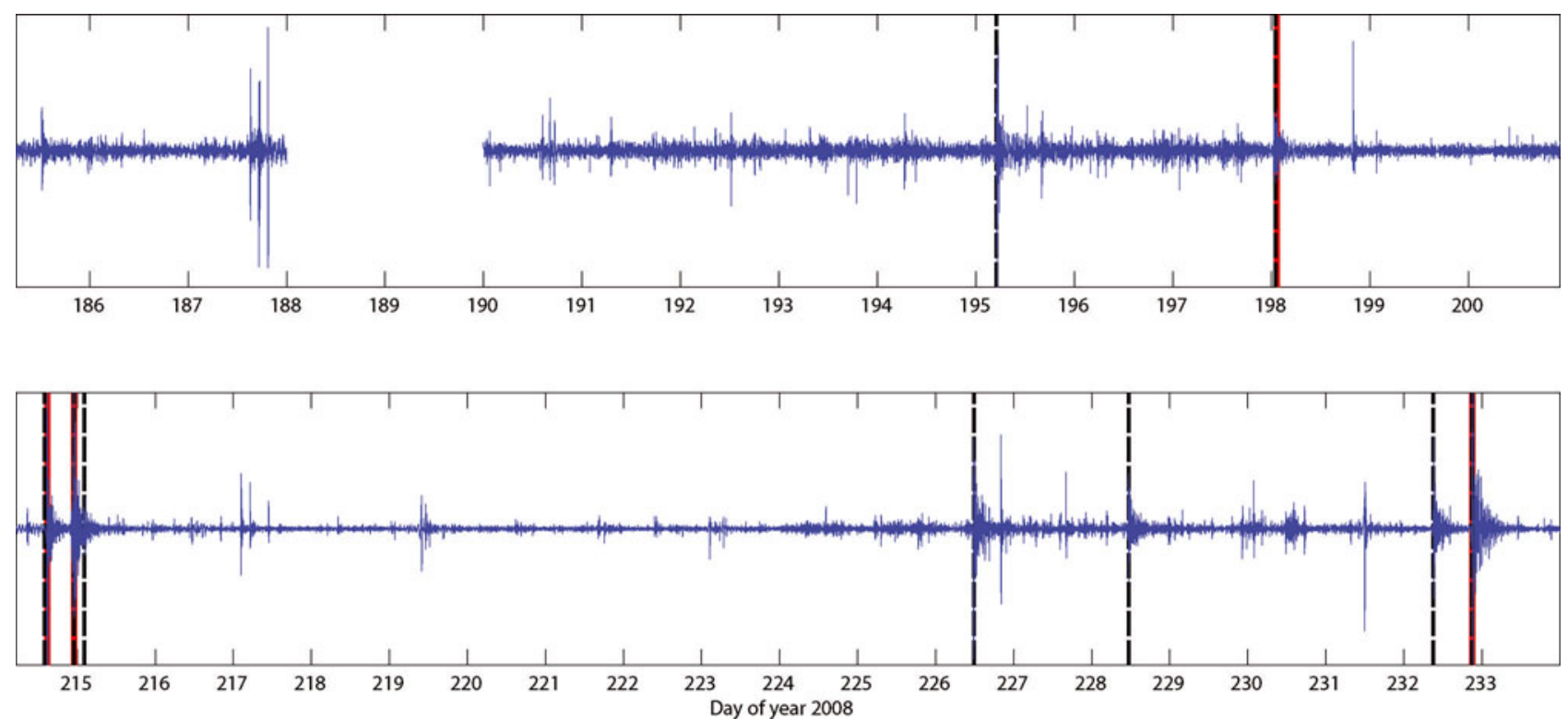

Fig. 2. (blue) 2008 tide-gauge record, bandpass-filtered from 200 to 4000 s, (red) times of globally detected glacial earthquakes, and (black, dashed) calving observations from time-lapse camera on the fjord wall. The tide-gauge record was missing on days 188-189 and 201-213 because of a sensor malfunction.

only the seismic detections from Nettles and others (2008). Considering the simultaneous occurrence of events in all three 2008 datasets, we do not expect the lack of photographic data to have a significant effect on the 2007 results.

To assess the influence of melt, independent of the calving-related velocity changes, we subtract the offsets caused by the calving events from the GPS velocity record for all days subsequent to each event.

Experimentation shows that, for events occurring late in the day, the accompanying velocity increase is primarily reflected in the following day's mean velocity. Therefore, for events occurring later than 18:00 UTC on a given day, the subsequent days were corrected with the difference between the current and the next day's velocities in order to adjust the remaining time series for the increase in speed.

For events occurring earlier than 18:00 UTC, the correction of all subsequent days is made with the speed difference between the day of the event and the previous day.

Following correction for calving-related velocity jumps, we remove the mean and a single, best-fitting trend from the time series for each GPS station; the latter accounts approximately for the effects of advection of the station through the glacier flow field. This approximate advection correction will also remove any long-term trend due to meltwater input, but the trend in meltwater input is nearly flat during our observing interval, and the correction enhances our ability to study daily flow variations. For the dates on which maintenance visits were made to the stations, causing artificial displacements of the antennas, the average of the previous day's and the next day's speeds is assigned. For data gaps, values are linearly interpolated between the end-points of the gap.

In the following analysis we assume that other external controls on the glacier flow velocity are negligible. For example, the ocean tides have been shown to affect the flow speed of the glacier on sub-daily timescales (de Juan and others, 2010), but their effect on estimates of daily average velocities is small.

Figure 3 shows the resulting corrections (calving and advection) for station IS25 (2007), as an example. In the remainder of this work, we refer to the velocity time series corrected in this manner as 'calving-corrected' velocity

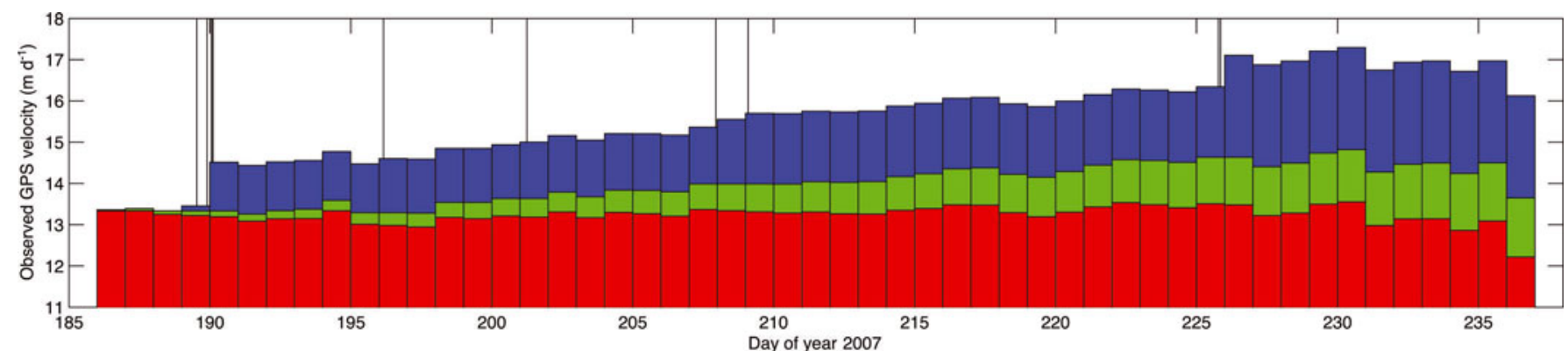

Fig. 3. Glacier velocity at GPS station IS25 in 2007, corrected for stepwise changes in velocity caused by glacial earthquakes and for advection. Blue bars show the raw time series, green bars the time series corrected for glacial earthquakes, red bars the time series with advective term subtracted. Black lines show times of detected glacial earthquakes. 
records. No large changes in flow azimuth are associated with the changes in speed we observe, so we use the terms 'speed' and 'velocity' interchangeably throughout this study.

\section{Melt records}

We estimated the melt history at each station location using a distributed surface-energy-balance (SEB) model of Helheim Glacier (Andersen and others, 2010). The SEB model was driven by observations from an AWS operated on the glacier trunk for 27 and 49 days in 2007 and 2008, respectively (Fig. 1). The AWS recorded standard meteorological parameters, with which meltwater production at the surface was estimated. To distribute the model from one point to the entire glacier, we used a 2006 digital elevation model derived from an Advanced Spaceborne Thermal Emission and Reflection Radiometer (ASTER) image (Stearns, 2007) and the MOD10A1 Daily Snow Albedo product derived from Moderate Resolution Imaging Spectroradiometer (MODIS) observations (D.K. Hall and others, http:// nsidc.org/data/index.html). The model area was $\sim 515 \mathrm{~km}^{2}$ and comprised model cells on ice with elevations less than $1000 \mathrm{ma.s.l}$. Further details are given by Andersen and others (2010).

We calculate melt records for days of year 208-234 in 2007, and days of year 183-232 in 2008. We express the daily values of melt as residuals, i.e. as deviations from mean melt (mm w.e.). We produce local melt records for all GPS sites, as well as an integrated record of the total melt within the model region, expressed as the average melt per unit surface area as a function of time.

The GPS and AWS data were primarily collected during the period of bare-ice exposure on the glacier. The time series thus do not represent the entire melt season, which is likely to begin in May and end in late September, based on records from the town of Tasiilaq. Early- or late-season variations will therefore not be captured by our measurements and estimates, but we are able to examine variations across the 7 weeks corresponding approximately to the middle of the melt season.

\section{METHODS}

In order to quantify the response of glacier flow speed to variations in meltwater generation at the surface, we develop a simple, linear model relating our melt-production time series to the calving-corrected observed flow-speed record. We evaluate the model results by comparing predicted velocities with observed values, using a measure of residual variance to assess goodness of fit. To allow for a time delay between melt and velocity response, we perform a temporal grid search (see below).

\section{Model}

Given our limited knowledge of the relationship between changes in meltwater supply and changes in flow velocity, we choose to assume a linear relationship between melt input and variations in flow speed. We use a least-squares approach to obtain the model sensitivity value, or admittance, that best explains the observed velocity data, given an input melt signal. We solve the linear matrix equation

$$
\mathbf{v}=\mathbf{M s}+\varepsilon
$$

for $\mathrm{s}$, minimizing the size of the error vector $\varepsilon$. $\mathbf{M}$ contains the melt records and $\mathbf{v}$ the calving-corrected observed

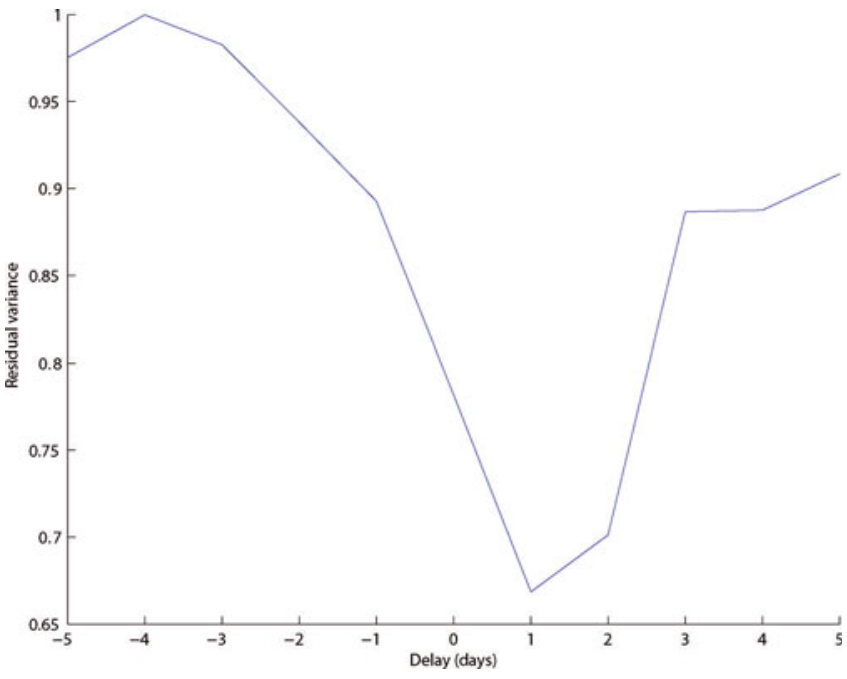

Fig. 4. Residual variance for models of glacier response to integrated melt at 2008 GPS station IS41, fitted for each lag/lead in a $[-5 ; 5]$ day interval. The best fit is obtained with velocity lagging melt input by 1 day.

velocity signals. All of the data are weighted equally. The model vector s simply contains the scalar sensitivity parameter(s) we seek $\left(\mathrm{m} \mathrm{d}^{-1}\left(\mathrm{~mm} \text { w.e. } \mathrm{d}^{-1}\right)^{-1}\right)$; both quantities in the unit are expressed as variations from mean values).

We evaluate the goodness of fit by calculating the variance of the difference between the predicted and the observed velocities, normalized by the variance of the observed velocity signal:

$$
\text { Res. var. }=\frac{\sum_{i=1}^{N}\left(v_{i}-\hat{v}_{i}\right)^{2}}{\sum_{i=1}^{N}\left(v_{i}-\bar{v}\right)^{2}}
$$

in which $N$ is the number of days in the time series, $v_{i}$ is the observed velocity value on day $i, \hat{v}_{i}$ is the predicted velocity value on day $i$ and $\bar{v}$ is the mean value of the observed velocity time series, which in this context is equal to zero, since the observed signal has already had the mean removed. The residual variance is then a measure of how much of the surface velocity signal remains unexplained by the melt-input model, such that a value of 1 indicates total lack of prediction, and a value of 0 , perfect prediction.

\section{Temporal grid search}

To allow for a possible time lag between the melt and velocity signals, we perform a temporal grid search in which we shift the velocity signal in 1 day steps over the interval $[-5 ; 5]$ days relative to the melt signal. We perform the linear inversion for a sensitivity value at each step, which yields 11 sensitivity values with which we compute 11 model velocity records. The lowest residual variance for this suite of models is found at a lag of 1 day, consistent with the optimal cross-correlation lag found by Andersen and others (2010) using a nearly identical dataset. An example of the results from this analysis, for a station near the calving front (IS41, 2008), is shown in Figure 4. Figure 5 shows the melt signal for the location of 2008 GPS station IS41 together with the calving-corrected daily IS41 mean velocity values, after the shift is applied. In the following analysis, we delay the velocity signal by 1 day relative to the melt signal to correspond to the best fit found in the grid search above. We do not allow for any further time delays. 


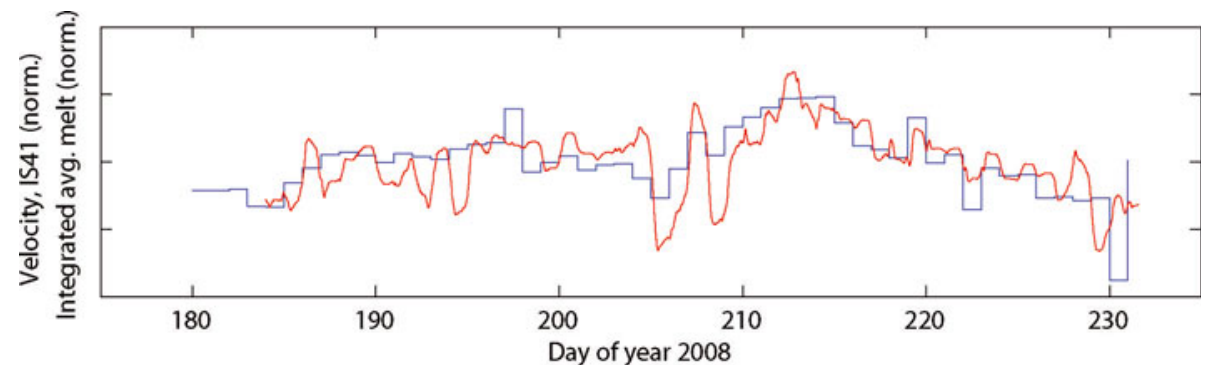

Fig. 5. Comparison of (blue) calving-corrected velocity signal for 2008 location IS41 with a 1 day lag applied, and (red) integrated average melt. Records are normalized for comparison. Melt signal is calculated hourly, but smoothed with a 24 hour running average.

\section{ANALYSIS AND RESULTS}

We first test a simple model in which the glacier response to meltwater input is required to be uniform in space and time; we then assess the need for further complexity.

\section{Spatial variability}

\section{Spatially uniform melt sensitivity}

We first assume that the velocity of all areas of the glacier is equally sensitive to variations in melt and thus solve for one sensitivity value for the entire glacier. We perform the fit separately for 2007 and 2008. Using the integrated glaciermelt record as the input signal leads to sensitivity values of $0.02 \mathrm{~m} \mathrm{~d}^{-1} / \mathrm{mm}$ w.e. $\mathrm{d}^{-1}$ for both 2007 and 2008, with fairly large residual-variance values of 0.87 for 2007 and 0.89 for 2008. Using the local melt records, we see sensitivity values of 0.006 and $0.007 \mathrm{~m} \mathrm{~d}^{-1} / \mathrm{mm}$ w.e. $\mathrm{d}^{-1}$ for 2007 and 2008, respectively. The fit using the local records produces slightly larger misfit values of 0.92 for 2007 and 0.89 for 2008. The resulting model fits from a single glacier-wide sensitivity value are illustrated in Figure 6 . The correlation between melt and velocity variations seen here is consistent with the results of Andersen and others (2010). Andersen and others (2010) found spatial variability in the strength of the correlation of melt and velocity variations, suggesting the possibility of a spatially varying pattern of glacier sensitivity to melt input.

\section{Spatially varying melt sensitivity}

To test for possible spatial variability in velocity sensitivity to melt input, we determine the model parameters (sensitivities) locally by solving for $s$ in Equation (1) at each GPS station location, thereby acquiring one sensitivity value per site. We experiment with using both the integrated and local melt records as input to the model.
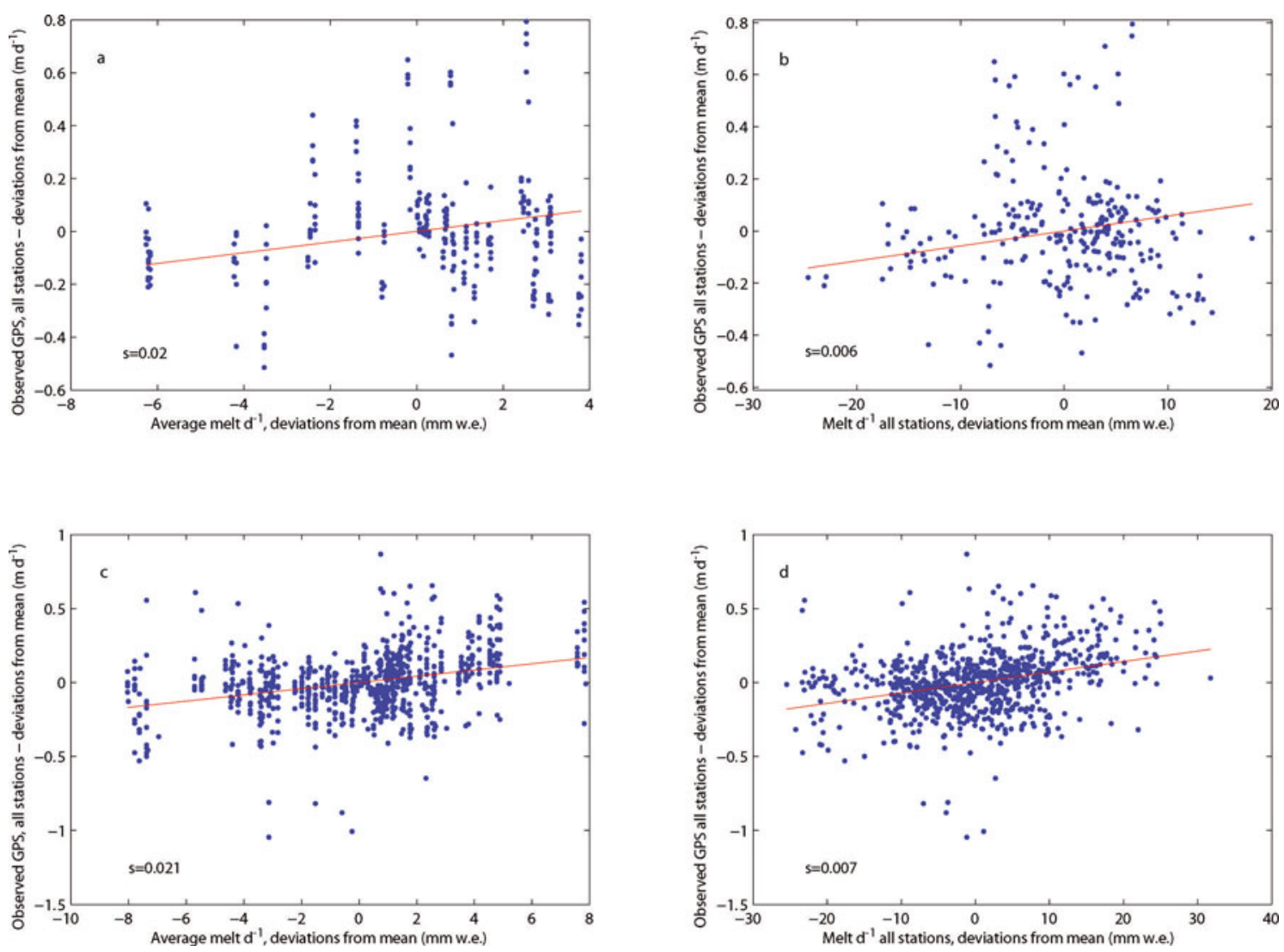

Fig. 6. Results of melt-sensitivity model using a single, spatially invariant sensitivity parameter, s, for $(a, c)$ integrated melt and (b, d) local melt versus GPS-station velocities in (a, b) 2007 and (c, d) 2008. Red line is best fit after Equation (1). 

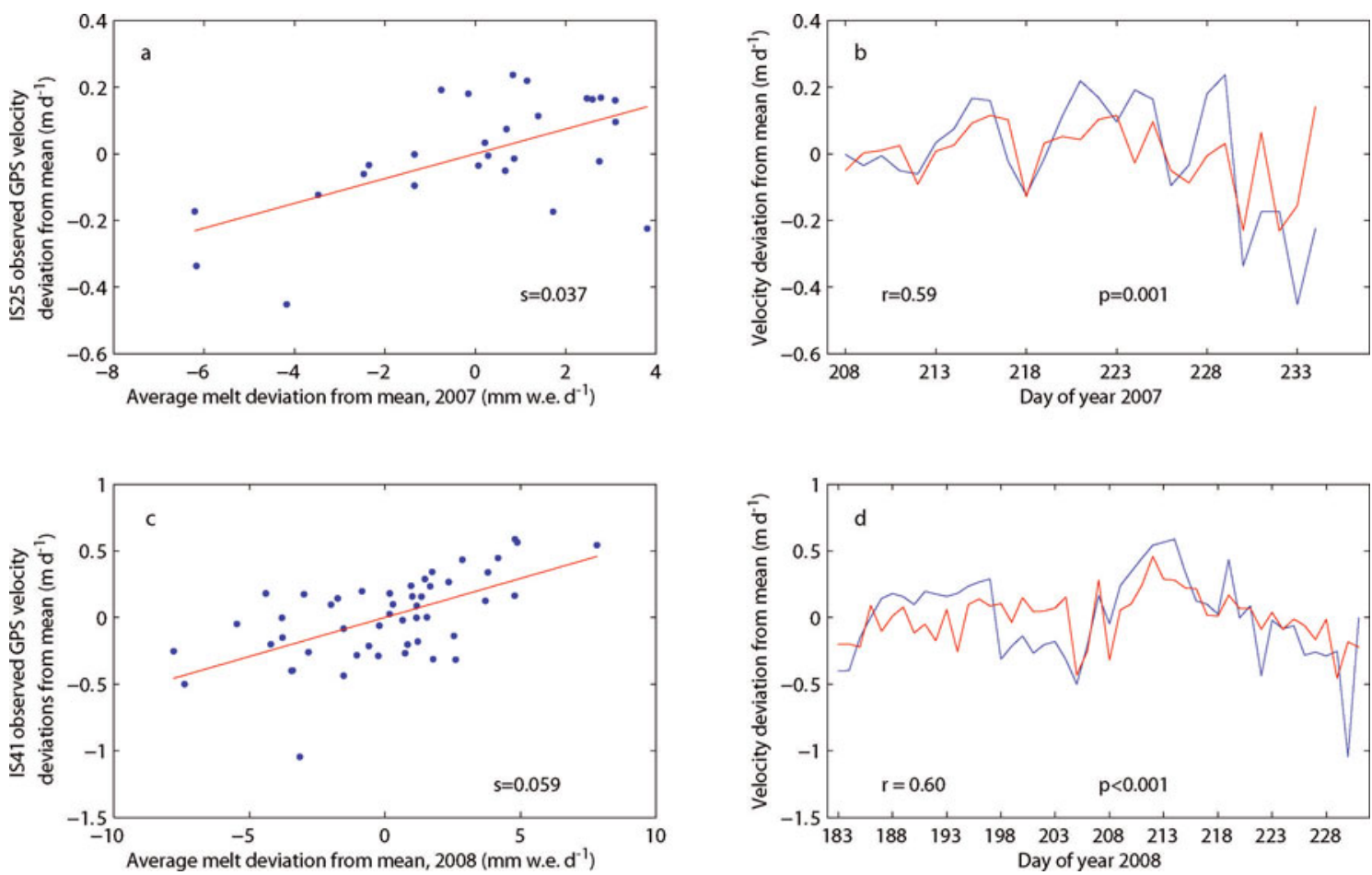

Fig. 7. Model fit at stations IS25 and IS41 in 2007 and 2008. (a) Scatter plot of deviations from mean melt, $12 \mathrm{~mm}^{\text {w.e. }} \mathrm{d}^{-1}$, and deviations from mean velocity, $15.6 \mathrm{~m} \mathrm{~d}^{-1}$, for GPS station IS25 in 2007. Red line shows best fit with slope $s=0.037$, i.e. $\sim 4 \mathrm{~cm} \mathrm{~d}^{-1}$ increased velocity per mm w.e. melt above mean. (b) Predicted (red) and observed (blue) velocities. Correlation coefficient $r=0.59$ between modeled and observed velocities is significant at $>99 \%$ levels. (c) Scatter plot of deviations from mean melt, $11.5 \mathrm{~mm}$ w.e. $\mathrm{d}^{-1}$, and deviations from mean velocity, $18.4 \mathrm{~m} \mathrm{~d}^{-1}$, for GPS station IS41 in 2008. Red line shows best fit with $s=0.059$, i.e. $\sim 6 \mathrm{~cm} \mathrm{~d}^{-1}$ increased velocity per mm w.e. melt above mean. (d) Predicted (red) and observed (blue) velocities. Correlation coefficient $r=0.66$ between modeled and observed velocities is significant at $>99 \%$ levels.

Using the integrated melt signal as the input, we find residual-variance values of $0.66-1.0$ for 2007 , and values of $0.64-1.0$ for 2008. Using the local melt records as input produces slightly poorer fits, with residual-variance values in the range $0.75-1.0$ in 2007 and $0.65-1.0$ in 2008. Thus, it appears that some stations do not respond to melt variations at all (residual variances of 1.0) while melt variations explain up to one-third of the calving-corrected velocity signal at other stations. Given the slightly better fits using the integrated melt, and its greater simplicity, we use the integrated melt record in the discussion that follows.

In general, stations located closer to the calving front appear more sensitive to melt input than those further away. Stations IS41 (2008) and IS25 (2007), located 4 and $6 \mathrm{~km}$ behind the calving front, are representative of near-terminus behavior; fits to the data are shown in Figure 7 . The majority of the melt-producing catchment is located upstream of these stations, and it is perhaps not surprising that the average integrated melt signal fits the velocity data from these stations well. Residual variances for stations IS25 and IS41 are 0.66 for 2007 and 0.64 for 2008, implying that $\sim 34-36 \%$ of the calving-corrected velocity behavior can be explained by melt variations (Fig. 7). The sensitivity values determined in this inversion are 0.04 and $0.06 \mathrm{~m} \mathrm{~d}^{-1}\left(\mathrm{~mm} \text { w.e. } \mathrm{d}^{-1}\right)^{-1}$ for 2007 and 2008, respectively. As an example, the sensitivity calculated for 2008 indicates that an increase in integrated melt of $5 \mathrm{~mm}$ w.e. $\mathrm{d}^{-1}$, above the $11.5 \mathrm{~mm}$ w.e. $\mathrm{d}^{-1}$ mean, prompts a $0.3 \mathrm{~m} \mathrm{~d}^{-1}$ velocity increase above the mean of $18.4 \mathrm{~m} \mathrm{~d}^{-1}$ (Fig. 7).

The variation in sensitivity to melt input with distance from the calving front is shown in Figure 8. A clear decrease in sensitivity with increasing distance along the flowline is apparent. A regression analysis shows that the correlation of sensitivities to distance from the calving front is significant at $>99 \%$ levels (Fig. 8a). When three stations with high residual-variance values and short time series are identified as outliers (IS40, IS46 and IS56, marked with red diamonds in the figure), an exponential fit to the data is preferable. The root-mean-square (RMS) residual of the linear fit is $0.015 \mathrm{~m} \mathrm{~d}^{-1}\left(\mathrm{~mm} \text { w.e. } \mathrm{d}^{-1}\right)^{-1}$, while the RMS residual of the exponential fit is $0.006 \mathrm{~m} \mathrm{~d}^{-1}\left(\mathrm{~mm} \text { w.e. } \mathrm{d}^{-1}\right)^{-1}$.

To test the impact of our calving-correction scheme on the retrieved sensitivity values and the observed spatial pattern, we repeat the same analysis for 2008 after correcting for only the three largest earthquake events (two on day 214 and one on day 232). Doing so leads to slightly lower sensitivity values (within $1 \sigma$ ) and slightly higher misfits overall. The spatial dependence of the sensitivities changes very little, however, indicating the robustness of this result to the details of the time-series correction.

\section{Temporal variability}

We also wish to investigate potential temporal variation in the sensitivity of glacier velocity to meltwater input. The available melt record from 2007 is relatively short (27 days), so we focus this analysis on data from 2008, when the melt record is longer (49 days). We calculate sensitivities and residual variances for five moving windows of lengths 5, 11, 15, 19 and 21 days, for eight stations selected from across the glacier trunk in 2008 (IS41, IS42, IS43, IS44, IS51, IS53, IS58 and IS61; Fig. 1), beginning at the first day of overlap between the melt record and the 

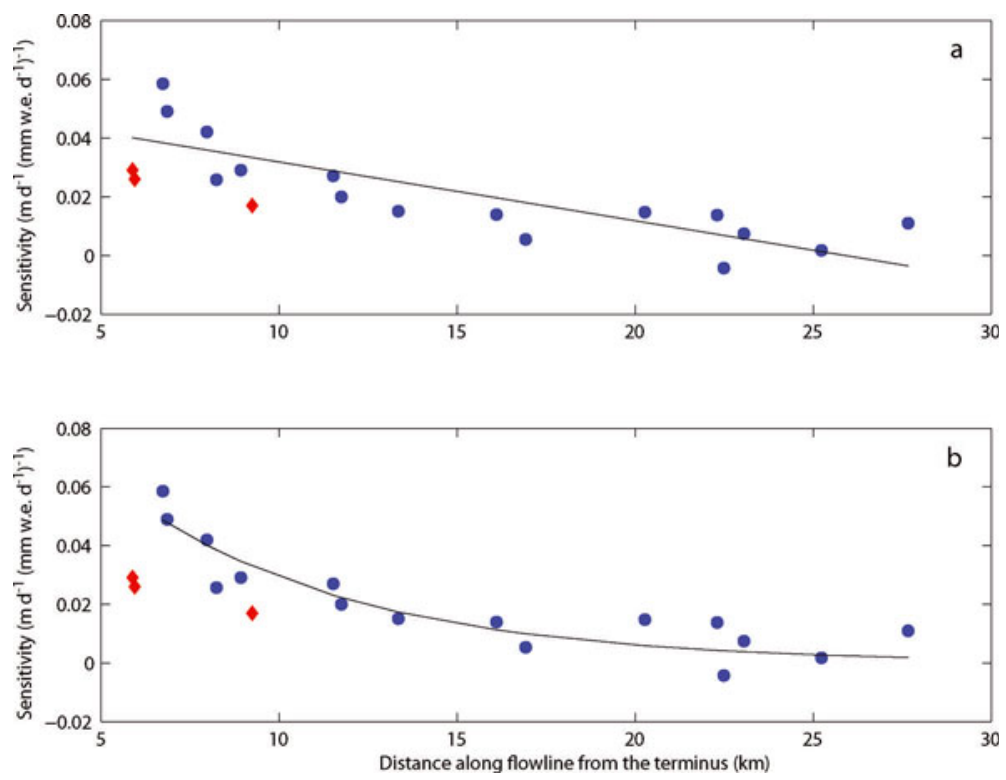

Fig. 8. (a) Distance from terminus, plotted with spatially varying sensitivity values for 2008. RMS residual of the linear fit is $0.015 \mathrm{~m} \mathrm{~d}^{-1}\left(\mathrm{~mm} \text { w.e. } \mathrm{d}^{-1}\right)^{-1}$. $r$ value of the correlation is -0.8 with $p=0.00006$. Points with short time series $(<35$ days $)$ are marked with red diamonds and are omitted in the fit. (b) Same as (a), but with an exponential relationship fitted to the points. RMS residual is $0.006 \mathrm{~m} \mathrm{~d}^{-1}\left(\mathrm{~mm} \text { w.e. } \mathrm{d}^{-1}\right)^{-1}$.

velocity time series. We repeat the fitting procedure with shifts of 1 day until the end of the moving window reaches the last day of overlap between the two time series. Thus, for each station, we generate five time series of sensitivity and residual variance. Figure 9 shows the 11, 15 and 19 day windows for station IS41.
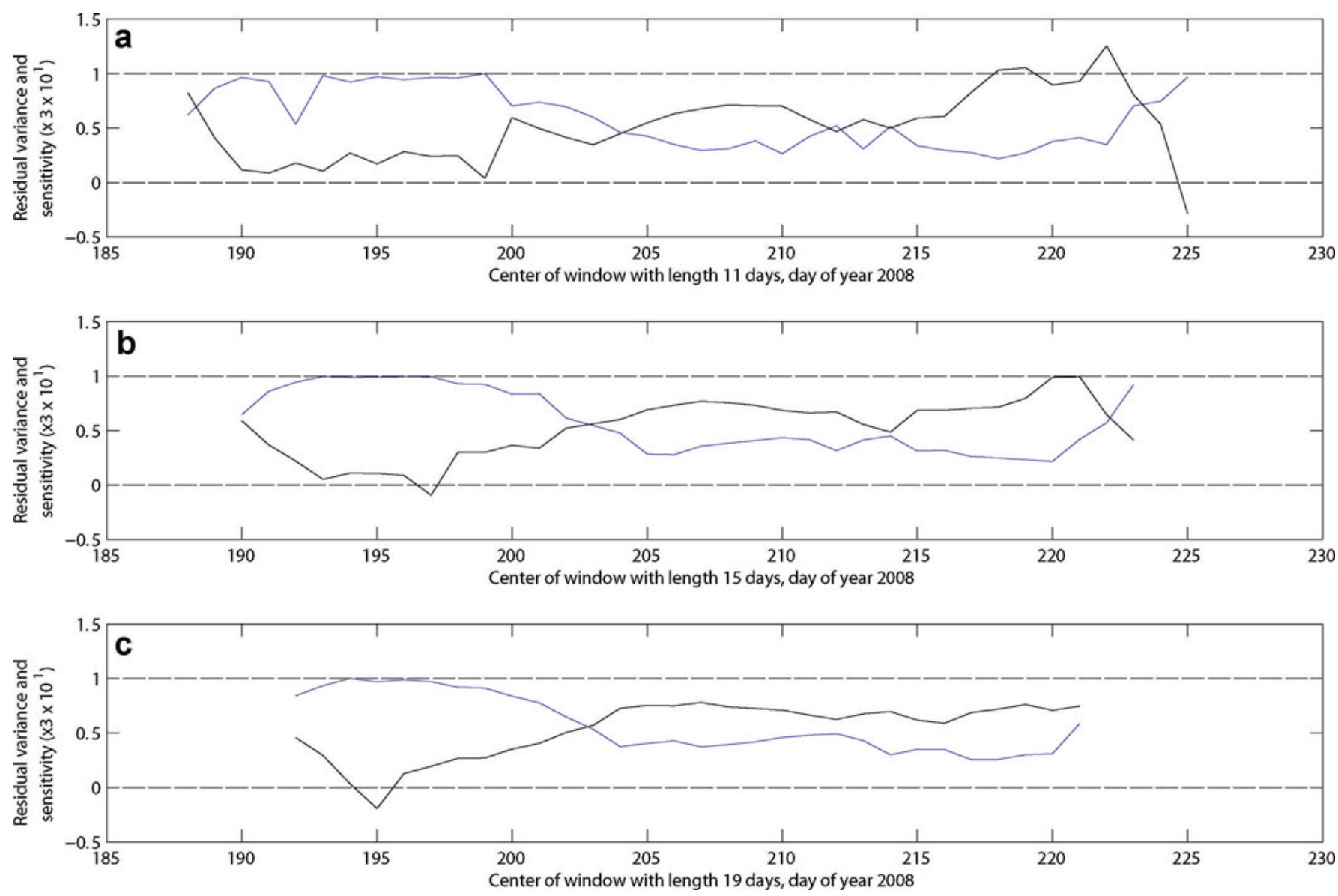

Fig. 9. Result of sliding-window inversion using integrated melt signal and 2008 GPS station IS41. Black curve shows sensitivity, blue curve shows residual variance. (a) 11 day window; (b) 15 day window; (c) 19 day window. 


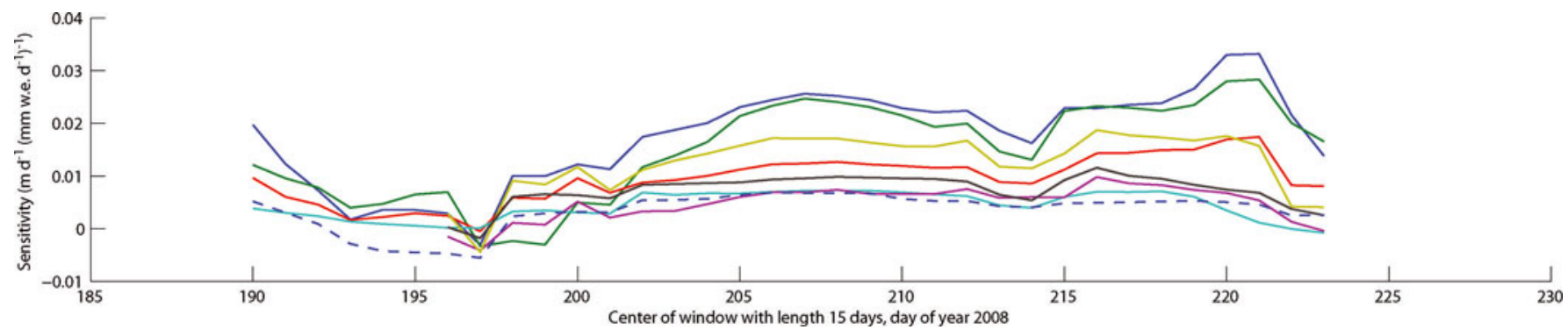

Fig. 10. Development of sensitivity values over the season for eight representative stations using a 15 day window: IS41 (blue), IS42 (green), IS43 (yellow), IS44 (red), IS51 (cyan), IS53 (blue, dashed), IS58 (purple), IS61 (black).

The curves produced by the five window lengths resemble each other, increasing in smoothness with window length, as a natural consequence of the longer averaging. A gradual decrease in residual variance over the considered period is evident, with the lowest residual variances occurring when the window is centered around days $219 \pm 1$. This is the case for all five tested window lengths. Residual variances of the windows centered around these days are as low as 0.22 (11 day window), 0.21 (15 day window) and 0.26 (19 day window), suggesting that melt input explains most of the calving-corrected velocity variability during these periods.

We also observe a change in the modeled sensitivity values. From the beginning of the time series, the sensitivity values first drop, then rise steadily and plateau in the interval from days 205 to 213, followed by a slight drop centered on day 214 . After day 214 the sensitivity values rise again, more steeply, and peak in the window centered on day 221-222. In Figure 9, this is especially clear in the 11 and 15 day windows. After the peak, the sensitivity values drop quickly in the 11 and 15 day windows (the 19 day window is not sufficiently long to capture this). While the different window lengths affect the precise timing of the variations (within \pm 1 day), the pattern seen across all windows is one of increasing sensitivity later in the season.

The same pattern is observed across the glacier, at all eight stations analyzed; the sensitivities calculated for the 15 day window are shown in Figure 10. As in the previous analysis, we observe the largest sensitivities at the stations nearest the glacier front. The observed temporal variation, with greater late-season sensitivity, also provides an explanation for the low sensitivities of sites IS40, IS46 and IS56, the outliers in the exponential fit shown in Figure 8; the time series are shorter for these three stations, and were recorded during the earliest part of the season.

\section{DISCUSSION}

Overall, we find that the total amount of velocity variability explained by melt at Helheim Glacier is small but significant. The observed additional speed-up of $\sim 3.5 \%(\sim 240 \mathrm{~m}$ $\mathrm{a}^{-1}$, using average 2008 summer speed measured close to the front) above the mean corresponds to an additional yearly solid-mass discharge of $\sim 0.9 \mathrm{Gt}$ from the trunk of Helheim Glacier. Using a common melt-sensitivity value across the entire glacier predicts the observed velocities poorly, whether using integrated or local melt records as input (Fig. 6). Allowing for separate sensitivity values at each station location produces better fits, with a coherent pattern of spatial variability. The sensitivity of velocity to melt input decays approximately exponentially with increasing distance from the calving front (Fig. 8). We also observe intraseasonal variability in the fraction of the velocity signal explained by varying meltwater input, with the fraction of variance explained by the model increasing later in the melt season. At the same time, we observe an increase in sensitivity (Fig. 9). The temporal pattern of this increase is similar among the stations, but the amplitude drops with distance up-glacier (Fig. 10).

We are unable to observe the subglacial hydrological system at Helheim Glacier directly, and literature on the subglacial hydrology of Greenland's large, marine-terminating outlet glaciers is limited. However, at glaciers where observations are available, strong correlations between variations in basal water pressure and variations in sliding velocity have been documented (e.g. Kamb and others, 1985, 1994; Iken and Bindschadler, 1986). Observations of surface displacement in combination with other hydrological and meteorological measurements used as a proxy for basal water pressure suggest a similar correlation (e.g. Björnsson, 1998; Anderson and others, 2004; Bartholomaus and others, 2008). A common interpretation of these studies is that an increase in basal water pressure causes or sustains cavitation, which leads to increased bed separation and consequently increased sliding speed. Similarly, we interpret the dependence of glacier speed on meltwater input that we observe at Helheim Glacier as resulting from increases in subglacial water pressure as surface meltwater drains to the bed.

Comparison with the results of previous studies considering the effect of meltwater-induced speed changes on the Greenland ice sheet and its outlet glaciers is complicated by the wide range of the timescales of these studies, which are both seasonal (e.g. Joughin and others, 2008b) and intraseasonal (e.g. Shepherd and others, 2009; Bartholomew and others, 2010; Howat and others, 2010). Joughin and others (2008b) showed that the West Greenland ice-sheet margin speeds up significantly (50-100\%, or 31-76 $\mathrm{m} \mathrm{a}^{-1}$ ) during the summer melt season compared with the annual mean speed. The effect on outlet glaciers in the same region was found to be smaller in a relative sense, but of similar absolute magnitude (9-14\%, or $51-77 \mathrm{~m} \mathrm{a}^{-1}$ ). The $\sim 3.5 \%$ of Helheim Glacier's summer speed variability we attribute to variations in melt input is somewhat lower than the relative seasonal speed-up observed by Joughin and others (2008b). However, the outlet glaciers studied by Joughin and others (2008b) have slower mean flow speeds than Helheim Glacier. We also note that those authors did not remove calving-related accelerations from their time series, possibly resulting in an overestimate of the fraction of acceleration attributed to melt. In addition, Joughin and others (2008b) 
used 24 day speed averages and a longer time series than is available to us, thereby perhaps capturing a seasonal signal we are unable to observe. Howat and others (2010) analyzed the flow-speed variability of a group of marineterminating outlet glaciers near Uummannaq, West Greenland. Among the stable glaciers, they typically found early-season speed increases followed by speed decreases. At one glacier (Rink Isbræ) they found intra-seasonal flowspeed variability of up to $25 \%$. At other glaciers, the variability was $<10 \%$, except in years of major lake-drainage events. Although these glaciers are relatively fast-flowing, we note that their peak speeds are less than half the midsummer background velocity of Helheim Glacier. The variations reported by Joughin and others (2008b) and Howat and others (2010) are on different timescales, but in both cases changes in basal water pressure are suggested as the cause of the speed variations.

Fractionally, the melt-related speed variability we observe at Helheim Glacier is also substantially smaller than that observed on the ice sheet by Shepherd and others (2009), on land-terminating Russell Glacier (Bartholomew and others, 2010) and on alpine glaciers (e.g. Iken and Bindschadler, 1986; Anderson and others, 2004).

In an absolute sense, the melt-related speed-up we observe is comparable to, or larger than, that seen on the ice-sheet margin and at some alpine glaciers. In the summers of 2007 and 2008, average flow speeds near the terminus of Helheim Glacier were $\sim 19-25 \mathrm{~m} \mathrm{~d}^{-1}$, or $7-9 \mathrm{~km} \mathrm{a}^{-1}$. The $2-4 \%$ speed-ups we observe in 2008 correspond to 140-365 $\mathrm{m} \mathrm{a}^{-1}$, about twice the magnitude of the absolute speed-up reported by Joughin and others (2008b) for the West Greenland outlet glaciers and slightly higher than the peak speed-up reported for Russell Glacier by Bartholomew and others (2010). At Columbia Glacier, Alaska, which is similar in size and also marine-terminating, Kamb and others (1994) and Meier and others (1994) studied the association between water storage, basal pressure and surface displacement and observed speed-up and slowdown events believed to be associated with subglacial pressure variations. At the downstream ' $\mathrm{km} \mathrm{59}$ ' site at Columbia Glacier, they observed speed variations of $\sim 0.5-2 \mathrm{~m} \mathrm{~d}^{-1}$, or $\sim 180-730 \mathrm{~m} \mathrm{a}^{-1}$, which is consistent with our results from Helheim. These authors, like Joughin and others (2008b), did not remove calvingrelated accelerations in their analysis.

The flow speed of Helheim Glacier responds less to meltwater input than the land-terminating ice-sheet margin, a land-terminating outlet glacier (Russell Glacier) or alpine glaciers, in a relative sense. Helheim's melt response is similar in amplitude to both the fractional and absolute velocity variations of West Greenland marine-terminating outlet glaciers. Despite the difficulties of comparing across timescales, glacier stability conditions, ice-front history and geographical region, we believe that the range of meltdriven velocity variations we find at Helheim Glacier is sufficiently similar to those seen elsewhere to allow the results of those studies to guide our interpretation.

We briefly summarize the group of observations that guide the formulation of a hypothesis regarding the subglacial drainage system of Helheim Glacier. First, our time series of flow speed (GPS) and climate parameters (AWS) begin after the melt season has commenced and end before melt ceases. This prevents us from observing the behavior of the glacier during the initial spring flood of meltwater, as well as when the melt stops; we are observing the middle of the melt season, probably shifted slightly towards the latter half. Second, the responsiveness of the glacier to variations in meltwater increases over the observation period. In the early part of our observation record, which corresponds to the middle of the melt season, the responsiveness is close to zero. Over the season, this increases strongly (Fig. 10). Third, this pattern is observed at all stations, but is amplified at stations closer to the ice front (Fig. 10). Fourth, Helheim Glacier has very high background flow velocities during the summer, and is believed to maintain high winter speeds also. This suggests sustained, high strain rates in the ice mass. Fifth, we expect a large amount of water to be present at the bed. The high flow velocity $\left(\sim 6-25 \mathrm{~m} \mathrm{~d}^{-1}\right.$ in the study region) is expected to generate large amounts of basal water due to frictional and strain heating, even in the absence of surface-meltwater input. Moreover, the Helheim catchment area is well defined and the outflow of runoff is confined to the glacial fjord. Nearly all meltwater will pass under the terminus. Also, the glacier surface is heavily crevassed, providing easy access for surface-generated meltwater to reach the englacial system. Sixth, several observations suggest high subglacial water pressure, especially near the front where the glacier is likely to be close to flotation (de Juan and others, 2010). Here the reported shape of the bed (https://www.cresis.ku.edu/data/greenland) is overdeepened behind the calving front, such that subglacial water will need to flow upslope to exit the glacier. In situ, we have observed turbid water upwelling into an open relict-moulin structure just behind the calving front, an additional indication of high basal water pressure.

The high strain rates observed at Helheim Glacier indicate that the maintenance of an arborescent-like system of few, large channels is unlikely. Conversely, since the water volume drained is assumed to be large, significant melt-back by heat dissipation is expected (Kamb, 1987). The balance between the strain closing of conduits and the opening of pathways by melt and pressure, averaged over a period, affects the subglacial drainage system's configuration and its sensitivity to added melt.

We suggest that the temporal changes in velocity sensitivity to melt variations we observe at Helheim Glacier are indicative of intra-seasonal changes in the subglacial hydrological system. Based on the estimated beginning and end of the Helheim melt season, we believe that our observations likely begin after the initial spring speed-up has occurred, placing the beginning of our time series within the subsequent slowed-down period described by Howat and others (2010). This is consistent with the relatively low and constant calving-corrected velocities observed near the beginning of the time series (Figs 3 and 5).

If the drainage system has been made more efficient during the early parts of the melt season as suggested by Howat and others (2010) for the Uummannaq glaciers, we assume that it is therefore able to handle the subsequent melt amount without causing observable changes in surface speed. This corresponds to the time period over which we observe zero or very low velocity sensitivity to melt variations, with nonzero sensitivity confined to the region of persistent high pressure just behind the calving front. As the season progresses into our observation period, and average melt levels remain relatively constant, the conduits initially formed are slowly closed off by strain deformation and the system is increasingly pressurized, leading to increasing velocity sensitivity to melt variations. 
The shorter-period, episodic fluctuations of heightened sensitivity we observe appear to be correlated with periods of high melt following periods of low melt. This is consistent with the idea of the basal hydrology adapting to an average water flux and thus reacting only to a flux increase beyond that which can be accommodated by the system at a given time. This is also consistent with the predicted behavior of a glacier 'flooded' with water at a rate exceeding the critical $Q$ described by Schoof (2010). The beginning of increased responsiveness is approximately coincident with a strong increase in melt after a lull around day 205 (Figs 5 and 10), keeping in mind that Figure 10 shows 15 day averages. We interpret this as a flooding of the drainage system, exceeding the glacier's current drainage capacity, resulting in a closer association between melt variations and velocity. Schoof (2010) suggests that high-frequency variability, similar to what we observe at Helheim Glacier, can have a stronger effect on glacier flow than a slower, steady increase in mean melt supply. Sensitivity decreases again near the end of our observing period, possibly because a new equilibrium has been attained by the drainage system, or because of a drop in meltwater production.

The overall picture is then one in which the subglacial hydrological system at Helheim Glacier is normally fairly highly pressurized, especially in the lower glacier behind the calving front. A sustained period of high meltwater flux may lead to a temporarily more efficient drainage system and lower velocity sensitivity to variations in meltwater input, as seen near the beginning of our observing period. As the drainage system is repressurized, probably due to the dominance of high strain rates over meltwater flux in controlling the character of the subglacial drainage system, velocity sensitivity to melt increases. The short-period (several days) variations we observe in sensitivity may indicate that, in the later part of the melt season, the existing drainage network is near capacity and can easily be flooded, increasing glacier response to meltwater variations. Other glacier characteristics, including details of the strain field across the glacier, may also be expected to modulate the glacier response, but are not explored further here.

The higher sensitivity we observe at times of greater melt indicates some nonlinearity in the responsiveness of Helheim Glacier to meltwater input, and suggests that an increase in background melt rates might lead to an increase in outlet-glacier sensitivity to that melt, in a weak positive feedback cycle. This nonlinear behavior is observed at least $20 \mathrm{~km}$ behind the calving front, suggesting that the area of increased sensitivity may extend with increasing temperatures to comprise a larger part of the glacier trunk. This interpretation has implications for glacier response to warming air temperatures, and merits further exploration.

\section{CONCLUSIONS}

We have investigated the impact of variations in meltwater input on surface velocity at Helheim Glacier using modelbased melt records and GPS-derived surface velocities. We find that, although melt-driven velocity variations represent only a few percent of the total glacier speed, the additional ice flux due to meltwater input is similar to that observed by other workers on the land-terminating portions of the icesheet margin. The sensitivity of glacier-speed variations to changes in meltwater input is spatially variable. It is highest near the front, as also suggested by Andersen and others
(2010), and decays approximately exponentially with distance along the flowline from the calving front. We interpret this spatial variation in melt sensitivity as resulting from higher basal water pressure closer to the calving front, perhaps associated with near-flotation conditions and a distributed subglacial drainage system.

We also find a temporal dependence in the fraction of velocity variance explained by meltwater input. In early July 2008, Helheim Glacier shows little or no dependence on melt input. In late July to mid-August, as much as $80 \%$ of the calving-corrected velocity variability can be explained by meltwater variations. Sensitivity to melt also increases, coincident with a week-long speed anomaly of 3-4\% above the mean near the calving front. We interpret the variations in sensitivity as the result of adaptation of the glacier's drainage system to evolving hydrological conditions, with the subglacial pressure generally increasing in the late summer. The temporal evolution in sensitivity to melt input indicates a nonlinear velocity response to surface melt, and points to the need for a better understanding of the response to melting, particularly as atmospheric temperatures rise.

We believe that our results are generally applicable to the group of Greenland's fast-flowing, marine-terminating outlet glaciers sharing common characteristics with Helheim (e.g. very high flow speeds and similar bed topography). Although the additional ice flux due to increased surface melting may represent only a few percent of the total flux through these high-discharge glaciers, the absolute magnitude of the additional flux may be substantial.

\section{ACKNOWLEDGEMENTS}

The Helheim 2007 and 2008 project was supported by the Gary Comer Science and Education Foundation, the US National Science Foundation, the Danish Commission for Scientific Research in Greenland (KVUG), the Spanish Ministry of Science and Innovation (MICINN), the Geological Survey of Denmark and Greenland (GEUS), Geocenter Copenhagen, the Danish National Space Center, NASA, the Lamont-Doherty Climate Center, and the Dan and Betty Churchill Exploration Fund. GPS equipment and technical support were provided by UNAVCO, Inc. We thank K. Schild for assistance in the field, and J. de Juan for assistance with data processing. We also thank two anonymous reviewers for comments that improved the manuscript.

\section{REFERENCES}

Amundson, J.M., M. Truffer, M.P. Lüthi, M. Fahnestock, M. West and R.J. Motyka. 2008. Glacier, fjord, and seismic response to recent large calving events, Jakobshavn Isbræ, Greenland. Geophys. Res. Lett., 35(22), L22501. (10.1029/2008GL035281.)

Amundson, J.M., M. Fahnestock, M. Truffer, J. Brown, M.P. Lüthi and R.J. Motyka. 2010. Ice mélange dynamics and implications for terminus stability, Jakobshavn Isbræ, Greenland. J. Geophys. Res., 115(F1), F01005. (10.1029/2009JF001405.)

Andersen, M.L. and 14 others. 2010. Spatial and temporal melt variability at Helheim Glacier, East Greenland, and its effect on ice dynamics. J. Geophys. Res., 115(F4), F04041. (10.1029/ 2010JF001760.)

Anderson, R.S. and 6 others. 2004. Strong feedbacks between hydrology and sliding of a small alpine glacier. J. Geophys. Res., 109(F3), F03005. (10.1029/2004JF000120.) 
Bartholomaus, T.C., R.S. Anderson and S.P. Anderson. 2008 Response of glacier basal motion to transient water storage. Nature Geosci., 1(1), 33-37.

Bartholomew, I., P. Nienow, D. Mair, A. Hubbard, M.A. King and A. Sole. 2010. Seasonal evolution of subglacial drainage and acceleration in a Greenland outlet glacier. Nature Geosci., 3(6), 408-411.

Björnsson, H. 1998. Hydrological characteristics of the drainage system beneath a surging glacier. Nature, 395(6704), 771-774.

Chen, J.L., C.R. Wilson and B.D. Tapley. 2006. Satellite gravity measurements confirm accelerated melting of Greenland ice sheet. Science, 313(5795), 1958-1960.

Das, S.B. and 6 others. 2008. Fracture propagation to the base of the Greenland Ice Sheet during supraglacial lake drainage. Science, 320(5877), 778-781.

De Juan, J. and 12 others. 2010. Sudden increase in tidal response linked to calving and acceleration at a large Greenland outlet glacier. Geophys. Res. Lett., 37(12), L12501. (10.1029/ 2010GL043289.)

Ekström, G. 2006. Global detection and location of seismic sources by using surface waves. Bull. Seismol. Soc. Am., 96(4A), 1201-1212.

Fountain, A.G., R.W. Jacobel, R. Schlichting and P. Jansson. 2005. Fractures as the main pathways of water flow in temperate glaciers. Nature, 433(7026), 618-621.

Hamilton, G.S. and 13 others. 2008. Iceberg calving and flow dynamics at Helheim Glacier, East Greenland, from time-lapse photography. [Abstract C13A-0565.] Eos, 89(53), Fall Meet. Suppl.

Howat, I.M., I. Joughin, S. Tulaczyk and S. Gogineni. 2005. Rapid retreat and acceleration of Helheim Glacier, east Greenland. Geophys. Res. Lett., 32(22), L22502. (10.1029/2005GL024737.)

Howat, I.M., J.E. Box, Y. Ahn, A. Herrington and E.M. McFadden. 2010. Seasonal variability in the dynamics of marine-terminating outlet glaciers in Greenland. J. Glaciol., 56(198), 601-613.

Iken, A. and R.A. Bindschadler. 1986. Combined measurements of subglacial water pressure and surface velocity of Findelengletscher, Switzerland: conclusions about drainage system and sliding mechanism. J. Glaciol., 32(110), 101-119.

Joughin, I., S. Tulaczyk, M. Fahnestock and R. Kwok. 1996. A minisurge on the Ryder Glacier, Greenland, observed by satellite radar interferometry. Science, 274(5285), 228-230.

Joughin, I. and 7 others. 2008 a. Continued evolution of Jakobshavn Isbræ following its rapid speed-up. J. Geophys. Res., 113(F4), F04006. (10.1029/2008JF001023.)

Joughin, I., S.B. Das, M.A. King, B.E. Smith, I.M. Howat and T. Moon. 2008b. Seasonal speed-up along the western flank of the Greenland Ice Sheet. Science, 320(5877), 781-783.

Kamb, B. 1987. Glacier surge mechanism based on linked cavity configuration of the basal water conduit system. J. Geophys. Res., 92(B9), 9083-9100.
Kamb, B. and 7 others. 1985. Glacier surge mechanism: 19821983 surge of Variegated Glacier, Alaska. Science, 227(4686), 469-479.

Kamb, B., H. Engelhardt, M.A. Fahnestock, N. Humphrey, M. Meier and D. Stone. 1994. Mechanical and hydrologic basis for the rapid motion of a large tidewater glacier. 2. Interpretation. J. Geophys. Res., 99(B8), 15,231-15,244.

Krabill, W. and 12 others. 2004. Greenland Ice Sheet: increased coastal thinning. Geophys. Res. Lett., 31(24), L24402. (10.1029/ 2004GL021533.)

Luthcke, S.B. and 8 others. 2006. Recent Greenland ice mass loss by drainage system from satellite gravity observations. Science, 314(5803), 1286-1289.

Meier, M. and 9 others. 1994. Mechanical and hydrologic basis for the rapid motion of a large tidewater glacier. 1. Observations. J. Geophys. Res., 99(B8), 15,219-15,229.

Nettles, M. and G. Ekström. 2010. Glacial earthquakes in Greenland and Antarctica. Annu. Rev. Earth Planet. Sci., 38, 467-491.

Nettles, M. and 12 others. 2008. Step-wise changes in glacier flow speed coincide with calving and glacial earthquakes at Helheim Glacier, Greenland. Geophys. Res. Lett., 35(24), L24503. (10.1029/2008GL036127.)

Rignot, E., J.E. Box, E. Burgess and E. Hanna. 2008. Mass balance of the Greenland ice sheet from 1958 to 2007. Geophys. Res. Lett., 35(20), L20502. (10.1029/2008GL035417.)

Schoof, C. 2010. Ice-sheet acceleration driven by melt supply variability. Nature, 468(7325), 803-806.

Shepherd, A., A. Hubbard, P. Nienow, M. McMillan and I. Joughin. 2009. Greenland ice sheet motion coupled with daily melting in late summer. Geophys. Res. Lett., 36(1), L01501. (10.1029/ 2008GL035758.)

Stearns, L.A. 2007. Outlet glacier dynamics in East Greenland and East Antarctica. (PhD thesis, University of Maine.)

Straneo, F. and 7 others. 2010. Rapid circulation of warm subtropical waters in a major glacial fjord in East Greenland. Nature Geosci., 3(33), 182-186.

Van de Wal, R.S.W. and 6 others. 2008. Large and rapid meltinduced velocity changes in the ablation zone of the Greenland Ice Sheet. Science, 321(5885), 111-113.

Van den Broeke, M., P. Smeets, J. Ettema, C. van der Veen, R. van de Wal and J. Oerlemans. 2008. Partitioning of melt energy and meltwater fluxes in the ablation zone of the west Greenland ice sheet. Cryosphere, 2(2), 179-189.

Van der Veen, C.J. 2007. Fracture propagation as means of rapidly transferring surface meltwater to the base of glaciers. Geophys. Res. Lett., 34(1), L01501. (10.1029/2006GL028385.)

Velicogna, I. and J. Wahr. 2006. Acceleration of Greenland ice mass loss in spring 2004. Nature, 443(7109), 329-331.

Zwally, H.J., W. Abdalati, T. Herring, K. Larson, J. Saba and K. Steffen. 2002. Surface melt-induced acceleration of Greenland ice-sheet flow. Science, 297(5579), 218-222. 